\title{
Mechanisms of Contrasting Korean Velar Stops: A Catalogue of Acoustic and Articulatory Parameters
}

\author{
Jana Brunner ${ }^{1}$, Susanne Fuchs ${ }^{1}$, Pascal Perrier ${ }^{2}$ \& Hyeon-Zoo Kim ${ }^{3}$ \\ ${ }^{1}$ Zentrum für Allgemeine Sprachwissenschaft,Berlin \\ ${ }^{2}$ Institut de la Communication Parlée, CNRS, INPG \& Univ. Stendhal, Grenoble \\ ${ }^{3}$ Department of French \& Literature of Dankook University \\ brunner@zas.gwz-berlin.de
}

\begin{abstract}
The Korean stop system exhibits a three-way distinction in velar stops among $/ \mathrm{g} /, \mathrm{k} /$ and $/ \mathrm{k}^{\mathrm{h}} /$. If the differentiation is regarded as being based on voicing, such a system is rather unusual because even a two-way distinction between a voiced and a voicless unaspirated velar stop gets easily lost in the languages of the world especially in the case of velar stops. One possibility for maintainig this distinction is that supralaryngeal characteristics like articulators' velocity, duration of surrounding vowels or stop closure duration are involved. The aim of the present study is to set up a catalogue of parameters which are involved in the distinction of Korean velar stops in intervocalic position.

Two Korean speakers have been recorded via Electromagnetic Articulography. The word material consisted of $\mathrm{VCV}$-sequences where $\mathrm{V}$ is one of the three vowels $/ \mathrm{a} /, / \mathrm{i} /$ or $/ \mathrm{u} /$ and $\mathrm{C}$ one of the Korean velars $/ \mathrm{g} /, / \mathrm{k}^{\prime} /$ or $/ \mathrm{k}^{\mathrm{h}} /$. Articulatory and acoustic signals have been analysed. It turned out that the distinction is only partly built on laryngeal parameters and that supralaryngeal characteristics differ for the three stops. Another result is that the voicing contrast is not a matter of one parameter, but there is always a set of parameters involved. Furthermore, speakers seem to have a certain freedom in the choice of these parameters.
\end{abstract}

\section{$1 \quad$ Introduction}

The voicing contrast in stops is often seen as the result of laryngeal activities, vocal fold vibration for voiced stops, lack of vocal fold vibration or aspiration for voiceless stops. Vibration of the vocal folds, however, demands a difference between sub- and supralaryngeal pressure (Fry 1982: 62f). The supralaryngeal pressure has to be lower than the pressure below the glottis. For stops this precondition of pressure difference is especially difficult to fulfil, since the mouth cavity is constricted at some point so that the air stream is blocked and the pressure behind the constriction increases with more and more air coming from the glottis. Velar stops are particularly affected, because the constriction is situated rather back so that the cavity behind the constriction becomes small and the pressure in this cavity increases quickly (Ohala 1983).

Looking at the languages of the world this results in an asymmetric typology for stops. Regarding the three most common places of articulation, bilabial, alveodental and velar, so called "voiced" and "voiceless" stops are not distributed evenly. Many languages have a "missing /g/" (Maddieson 1984: 2.6, 2003) which can be explained by the difficulties in producing a voiced velar. If, however, voicing gets lost, /g/ and / $/$ / can no longer be distinguished and merge. 
Korean, however, contradicts this general pattern in exhibiting not only a two-way but a three-way contrast for velar stops. At least in intervocalic position, this contrast is often described as being primarily based on voicing. The Handbook of the IPA, for example, describes $/ \mathrm{g} /$ as voiced in intervocalic position, $/ \mathrm{k}^{\prime} /$ as a voiceless unaspirated fortis stop syllable-initially, without saying anything about intervocalic position, and $/ \mathrm{k}^{\mathrm{h}} /$ as a strongly aspirated voiceless sound in the same position (Lee 1999: 112). Han and Weitzman (1970) distinguish aspirated, weak and strong stops and state that the weak stops are voiced between voiced sounds. Similarly, Umeda \& Umeda (1965) describe the "forced" and "aspirated" stops as voiceless and the "unaspirated" as voiced between two voiced sounds. Kim (1996) uses a different terminology and also different symbols. She calls the stops lenis, fortis and aspirated $\left(/ \mathrm{k} /, / \mathrm{k}^{\prime} /, / \mathrm{k}^{\mathrm{h}} /\right)$, which stresses her view that consonant voicing is not contrastive in Korean and that voiced stops are allophones of lenis stops in intervocalic position.

If it is already difficult to distinguish two velar stops merely by voicing, the question is how the three-way contrast in Korean is realized. One strategy could be to make use of supralaryngeal mechanisms. They could be aimed at intensifying the contrast produced by voicing in prolonging the voicing during closure. A number of supralaryngeal strategies to sustain voicing during closure have been proposed, for example by Houde (1968) and Ohala (1983), who suggested that forward movement performed by the tongue during velar stop closure aims at enlarging the cavity and thereby reducing the pressure behind the constriction so that voicing can be sustained for a longer period. For velar stops, however, those mechanisms seem to be especially difficult to perform, since the cavity behind the closure is particularly small. Other studies, however, contradict this view in saying that those loops are not performed in order to sustain voicing. Mooshammer et al. (1995), for example found for German that the loops are larger for $/ \mathrm{k} /$ than for $/ \mathrm{g} /$. Kent \& Moll (1972) propose airstream mechanisms as a reason for looping patterns, Perrier et al. (2003) suggest biomechanical reasons. Löfqvist \& Gracco (2002) propose cost minimization principles as a reason for looping patterns in that they regard the whole movement as being planned from the beginning of the first vowel to the end of the second vowel.

If supralaryngeal strategies do not sustain voicing they could nevertheless have a function in contrasting the stops. Parameters like vowel duration have been proved to influence the stop contrast (Luce \& Charles-Luce 1985). Other parameters such as stop closure duration or ratio of closure have also been proposed.

There are a number of acoustic studies of Korean velars (e.g. Cho et al. 2002, Choi 2002, Han \& Weitzman 1970, Kagaya 1971, 1974), and also a few on articulation, (Sawashima \& Park 1979 for final stops, Silverman \& Jun 1994 for consonant clusters, Hirose et al. 1974 for word initial stops). However, to our knowledge, there are no studies on the articulation of intervocalic stops.

The present study examines supralaryngeal as well as laryngeal parameters of the Korean velar stops and sets up a list of parameters that are involved in the distinction among velar stops. The characteristics of each stop will be described and possibilities of interspeaker variability will be referred to. Although vowel context has a strong influence on the distinction of the three stops, the contrast has been analysed independently of vowel context only so far. 


\section{$2 \quad$ Methods}

\subsection{Procedure}

Two Korean speakers, one male (SH) and one female (HS) were recorded via Electromagnetic Articulography (Carstens AG 100). This system is based on measuring induced current in a magnetic field, which is generated by three transmitter coils. The transmitter coils are attached midsagittally to a helmet on the subject's head (cf. fig. 1). There is one transmitter coil behind the neck, one near the chin and a third one near the forehead. Within the magnetic field a position dependent current is induced in five sensors ("receiver coils"). Two of them, one at the bridge of the nose, the other one at the upper incisors, serve as reference to enable compensation for head movements. The other three sensors are attached to the tongue, one at the tongue tip (tt), one at the tongue dorsum (td) and the third one at the tongue back $(\mathrm{tb})$. The sensors were located at equal distance from about $1 \mathrm{~cm}$ to about $5 \mathrm{~cm}$ from the tongue tip. Depending on the position of the sensors in the magnetic field the amplitude of the induced current changes and the movements of the tongue points can be tracked. The sampling frequency was $500 \mathrm{~Hz}$. For the purposes of this study only the data from the tongue back have been analysed.

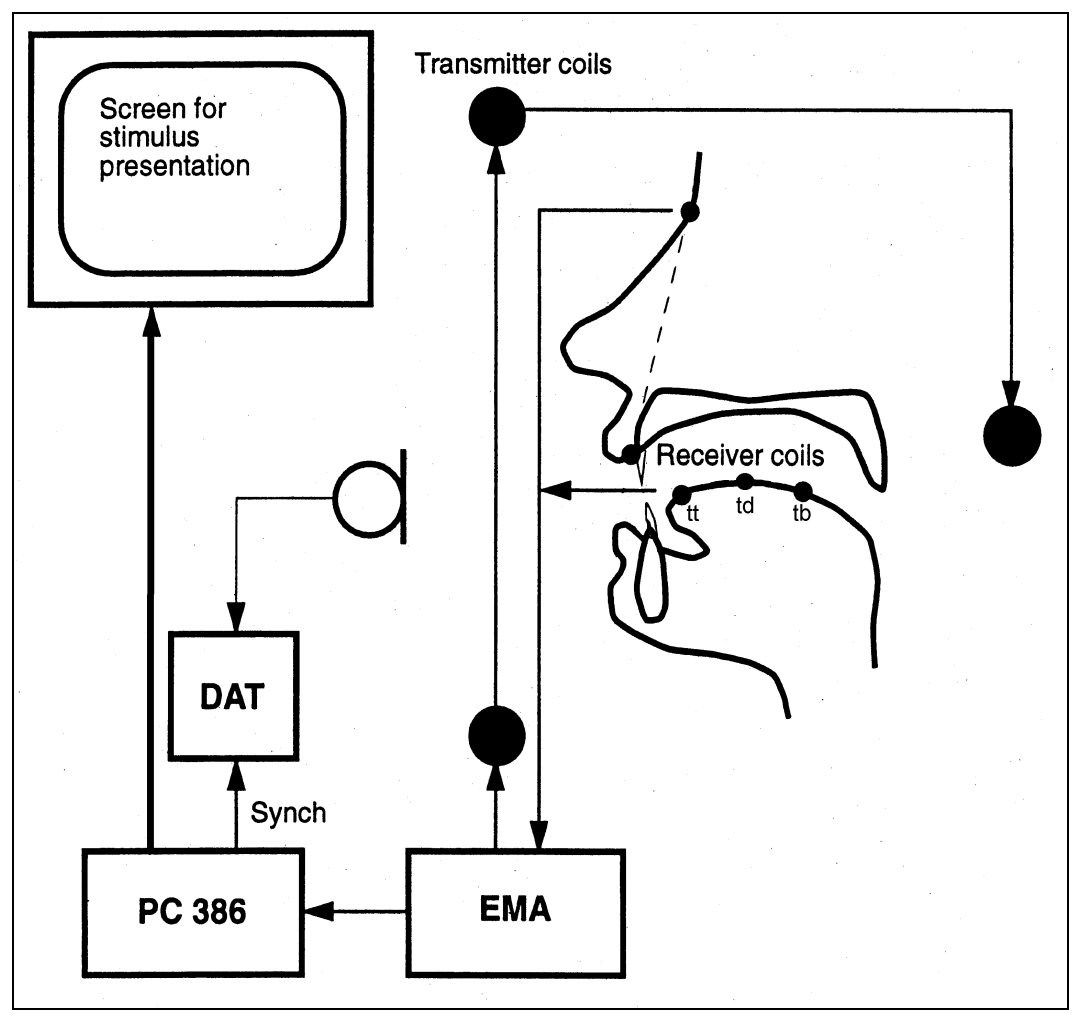

Figure 1: Electromagnetic Articulography

The word material consisted of 26 Korean words and one nonsense word. There was one word for each possible VCV-sequence where $\mathrm{V}$ is either $/ \mathrm{a} /, / \mathrm{o} /$ or $/ \mathrm{u} /$ and $\mathrm{C}$ one of the three velar stops. The nonsense word was chosen because there is no word for the sequence $/ \mathrm{uk}^{\mathrm{h}} \mathrm{u} /$ in Korean. There were two randomised sessions, each of the 27 words was repeated five times in succession in each session. For technical reasons, there was a time limit for the experiment. That is why carrier sentences could not be used. 
Table 1: word material

\begin{tabular}{|c|c|c|}
\hline word & VCV-sequence & English translation \\
\hline pagaci & /aga/ & gourd \\
\hline kak'ai & /ak'a/ & near \\
\hline $\mathrm{ak}^{\mathrm{h}}$ asia & $/ \mathrm{a} \mathrm{k}^{\mathrm{h}} \mathrm{a} /$ & acacia \\
\hline sagilo & /agi/ & made of chinaware \\
\hline ak'ita & /ak'i/ & to save money \\
\hline sak $^{\text {hita }}$ & $/ \mathrm{ak}^{\mathrm{h}} \mathrm{i} /$ & to grow \\
\hline paguni & /agu/ & basket \\
\hline pak'uta & /ak'u/ & to change \\
\hline sak $^{\text {h }}$ la & $/ \mathrm{ak}^{\mathrm{h}} \mathrm{u} /$ & cherry flower \\
\hline kigahata & /iga/ & to raise one's family \\
\hline cik'aci & /ik'a/ & you too \\
\hline mik $^{\mathrm{h}}$ ael & $/ \mathrm{ik}^{\mathrm{h}} \mathrm{a} /$ & -name- \\
\hline pigita & /igi/ & to be equal \\
\hline pik'ita & /ik'i/ & to illuminate obliquely \\
\hline pik ${ }^{h}$ ita & $/ \mathrm{ik}^{\mathrm{h}} \mathrm{i} /$ & to line up \\
\hline piguni & /igu/ & buddhist nun \\
\hline mik'ulaci & /ik'u/ & the loach \\
\hline mik ${ }^{\mathrm{h}}$ ulaci & $/ \mathrm{ik}^{\mathrm{h}} \mathrm{u} /$ & the loach \\
\hline pugahata & /uga/ & to add \\
\hline acuk'ali & /uk'a/ & ricinus \\
\hline $\mathrm{uk}^{\mathrm{h}}$ ano & $/ \mathrm{uk}^{\mathrm{h}} \mathrm{a} /$ & how to do? \\
\hline ukida & /ugi/ & to insist \\
\hline uk'ita & /uk'i/ & it is funny \\
\hline chuk $^{h_{\text {ita }}}$ & $/ \mathrm{uk}^{\mathrm{h}} \mathrm{i} /$ & to compliment \\
\hline suguhata & /ugu/ & to be conservative \\
\hline puk'umi & /uk'u/ & wheat pancake \\
\hline suk ${ }^{\mathrm{h}} \mathrm{uli}$ & $/ \mathrm{uk}^{\mathrm{h}} \mathrm{u} /$ & -nonsense word- \\
\hline
\end{tabular}

\subsection{Analysis}

\subsubsection{Acoustic segmentation and labelling}

Acoustic labelling marks specific events in the signal and thus divides it into segments. In this case the following segments were of interest: the first vowel (V1), the second vowel (V2), the closure, and voicing into closure, which is the voicing that still takes place after closure onset. Consequently, six events were labelled (cf. figure 2):

- the beginning of V1: onset of the second formant ${ }^{1}$,

- the end of V1 and beginning of closure: offset of the second formant,

- voice offset: the end of vibration of the glottis, in the oscillogram this is the end of clear periodic movement,

- the end of closure and beginning of aspiration: the burst,

- the end of aspiration and beginning of V2: onset of the second formant,

- the end of V2: offset of the second formant.

$1 \quad$ F2 onset was defined not as the point in time where the second formant becomes visible but where its intensity becomes characteristic for a vowel. F2 offset is the point where intensity gets lost. 


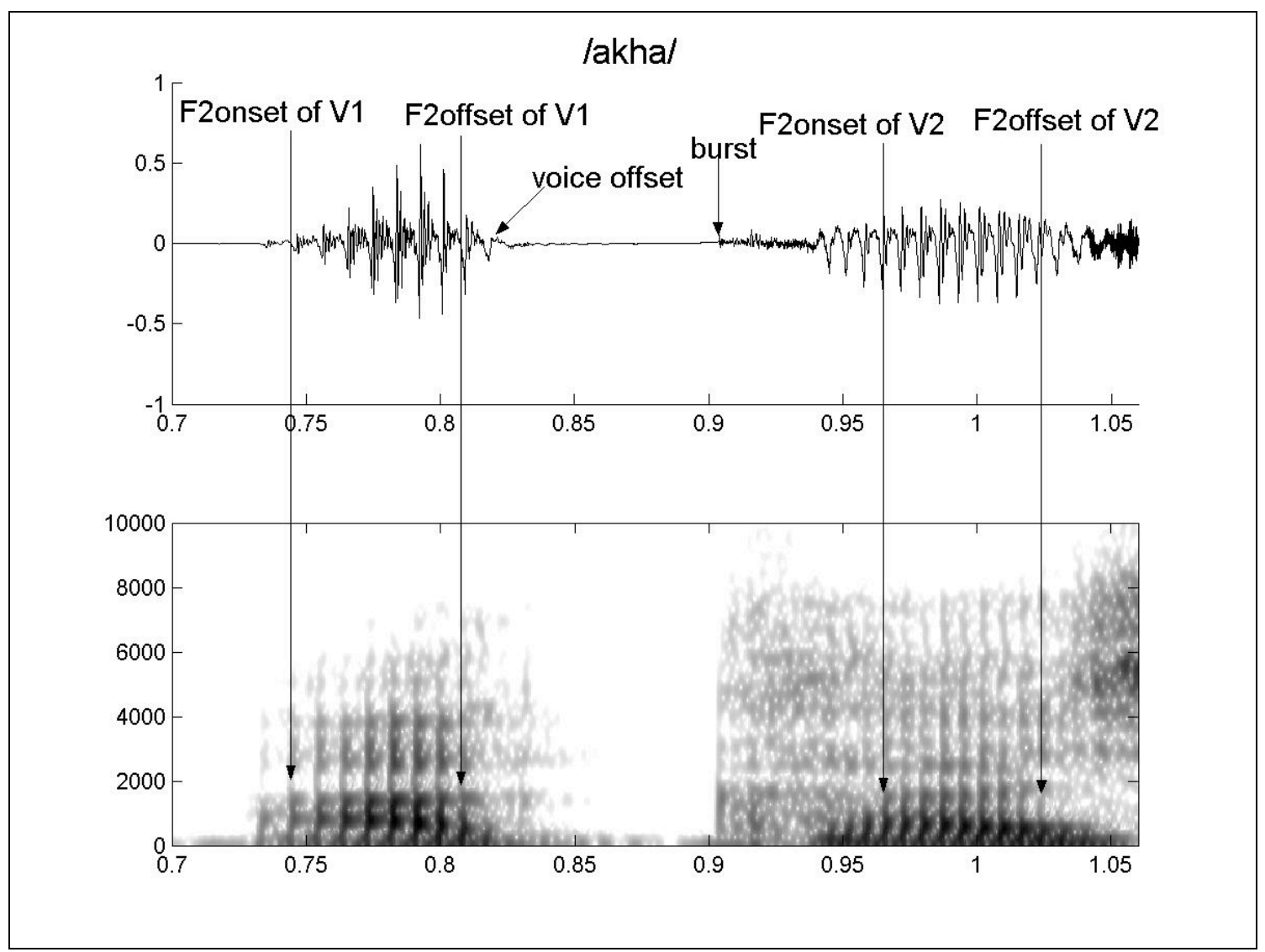

Figure 2: Oscillogram and spectrogramm for $/ a k^{h}$ a/ for speaker $\mathrm{SH}$

Acoustic labelling involved a number of problems which will be mentioned briefly. Especially for speaker $\mathrm{SH}$, there was often no closure for $/ \mathrm{g} /$, the tongue only approximated the palate without producing a closure. Consequently, it was impossible to measure a burst (cf. figure 3). On the other hand, especially for $/ \mathrm{k}^{\prime} /$ often multiple bursts were detected. In those cases the first one was considered as end of closure for following calculations. Furthermore, speaker HS pronounced the word "sukh uli" without the first $/ \mathrm{u} /:$ /sk ${ }^{\mathrm{h}} \mathrm{uli} /$. In this case F2 onset and offset of V1 could not be labelled. Additionally, because of technical problems with the first recording of /aga/ for speaker HS this recording could not be analysed. So there are only five repetitions of /aga/ for this speaker.

\subsubsection{Calculations}

In order to constitute a set of parameters that can be used to distinguish the stops from each other the following calculations were carried out.

\subsubsection{Segmental durations}

Sounds can often be distinguished by the duration of certain segments, either preceding or following the particular sound, or by the duration of certain subcomponents of the sound itself. A voiced stop, for example, normally has a longer voicing into closure than a voiceless stop. 


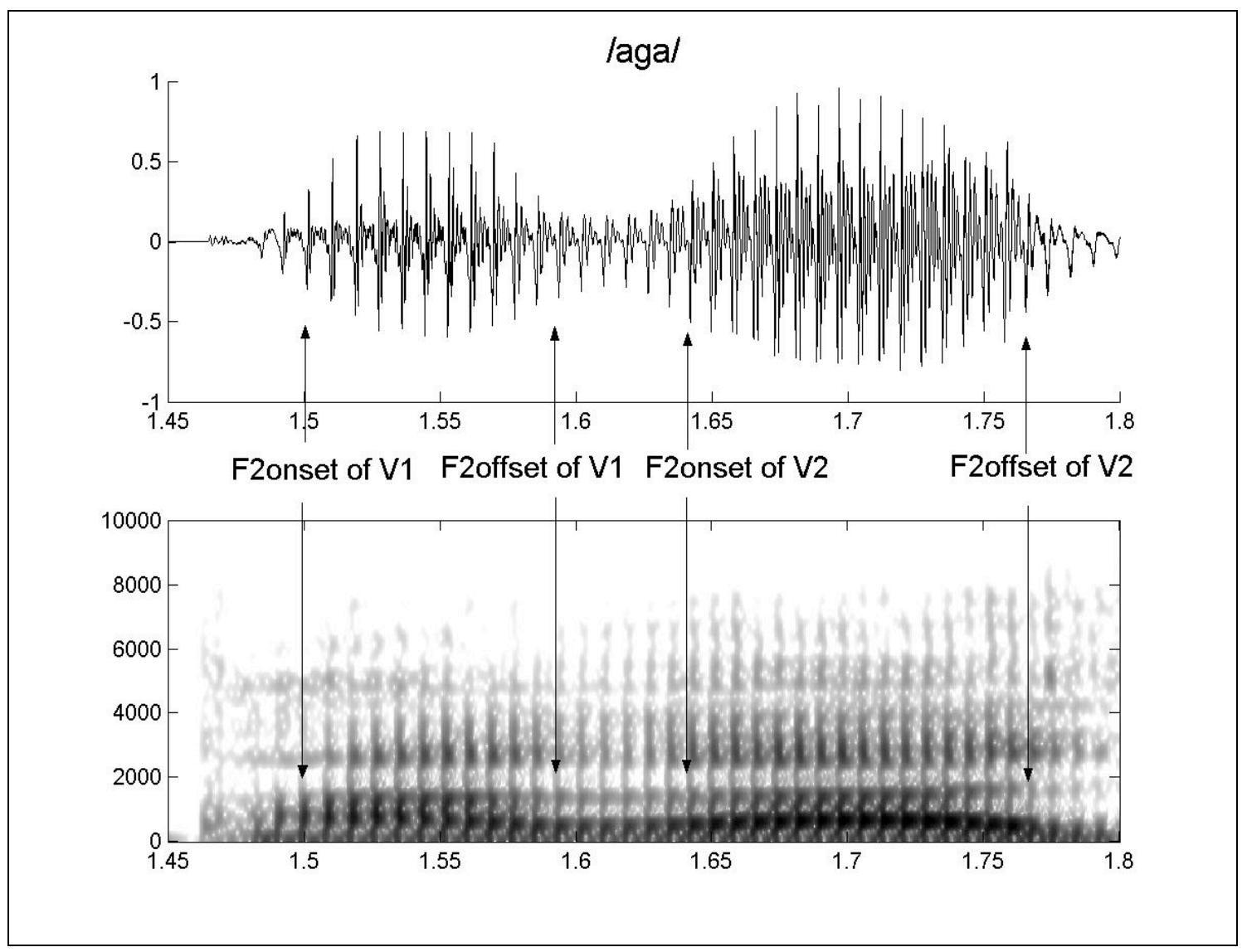

Figure 3: Oscillogram and spectrogramm for laga/ for speaker $\mathrm{SH}$

The following durations were analysed:

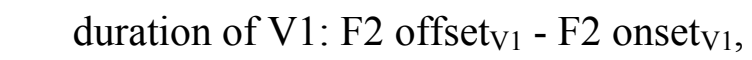

- voicing into closure: voice offset - F2 offset ${ }_{\mathrm{V} 1}$,

- closure duration: burst - F2 offset $_{\mathrm{V} 1}$,

- voice onset time: F2 onset 22 - burst (Klatt 1975),

- duration of V2: F2 offset 2 - F2 onsettr2,

- duration of the complete VCV-sequence: F2 offset ${ }_{\mathrm{V} 2}-\mathrm{F} 2$ onset $_{\mathrm{V} 1}$.

Furthermore, because the VCV-durations might differ depending on the stop, the percentages of the durations of $\mathrm{V} 1$, closure and $\mathrm{V} 2$ in relation to the VCV-duration were calculated.

\subsubsection{Movement amplitude}

The movement amplitude is the distance the tongue travels during a given interval. This parameter can tell, for example, how much the tongue moves during closure. It was calculated as the integral of the tangential velocity with the following formula:

$$
\text { movement amplitude }=\text { sum(tangential velocity/sampling rate) }
$$

The following movement amplitudes were calculated:

- movement amplitude during V1,

- movement amplitude during closure,

- movement amplitude during V2,

- movement amplitude during the VCV-sequence. 


\subsubsection{Euclidean distance}

The Euclidean distance is the straight line distance between two points. It differs from movement amplitude in that it is not the way the tongue really moves along but the way it should move if it was taking the shortest path.

The Euclidean distance was calculated via the following formula:

$$
\text { Euclidean distance }=\sqrt{ }\left(\left(x_{1}-x_{2}\right)^{2}+\left(y_{1}-y_{2}\right)^{2}\right)
$$

with $\mathrm{x}_{1}$ and $\mathrm{y}_{1}$ being the coordinates of the starting point and $\mathrm{x}_{2}$ and $\mathrm{y}_{2}$ being the coordinates of the endpoint.

The following Euclidean distances have been calculated:

- Euclidean distance during V1,

- Euclidean distance during closure,

- Euclidean distance during V2,

- Euclidean distance during the VCV-sequence.

\subsubsection{Quotients of Euclidean distance and movement amplitude}

To find out to which degree the path is curved the quotient of Euclidean distance and movement amplitude has been calculated. This ratio cannot exceed 1, since the Euclidean distance cannot be longer than the movement amplitude. If the result is near 1 this means that the tongue is taking a nearly direct way, whereas if the number is very small the tongue moves in a big loop (Löfqvist 2002).

The quotients follow from what has been measured for movement amplitudes and Euclidean distances.

\subsubsection{Tangential velocities}

Velocities at certain points can also characterise the movement and consequently a sound. For example, there is normally one velocity peak halfway between the middle of a vowel and closure onset. At closure onset, the velocity decreases extremely, so there should be a velocity minimum. If, however, the minimal velocity at that point is a lot higher for one stop than for another this could mean that there is no real closure for the first stop.

Peak and minimal velocities, which means the highest and the lowest velocity during the following sequences have been determined:

- from beginning to end of V1,

- from closure onset to closure offset,

- from beginning to end of V2,

- from beginning to end of the complete VCV-sequence.

Furthermore, the difference between peak velocity and minimal velocity for the whole sequence was calculated. This value tells something about velocity differences during the trajectory. If it is very high, the movement might be rather abrupt, whereas if it is rather small, the movement should be quite even. 


\subsubsection{Tongue position at closure onset}

Velar stops are produced in the velar region, however, they can differ in the exact place where the stop is produced. In German, for example, the aspirated velar stop is produced more fronted in an /i/-context than in other contexts. Therefore the x-coordinates of closure onset (F2 offset of V1) were determined.

\subsection{Parameter catalogue}

After all the measurements had been taken, 31 parameters were set up that might be involved in contrasting the three stops. In the table below the parameters are grouped into four classes according to the segment they refer to.

\section{Table 2: Parameters}

\section{a) VCV-movement}

1. duration

2. movement amplitude

3. Euclidean distance

4. Euclidean distance/movement amplitude

5. peak velocity

6. minimal velocity

7. peak velocity - minimal velocity

\section{b) $\mathbf{V 1}$}

8. duration of V1

9. movement amplitude of V1

10. Euclidean distance of V1

11. Euclidean distance/movement amplitude

12. percentage of $\mathrm{VCV}$-duration

13. peak velocity during $\mathrm{V} 1$

14. minimal velocity during $\mathrm{V} 1$

\section{c) $\mathbf{V 2}$}

15. duration of $\mathrm{V} 2$

16. movement amplitude of V2

17. Euclidean distance of V2

18. Euclidean distance/movement amplitude

19. percentage of VCV-duration

20. peak velocity during V2

21. minimal velocity during $\mathrm{V} 2$

d) stop closure

22. closure duration

23. movement amplitude of closure

24. Euclidean distance of closure

25. Euclidean distance/movement amplitude

26. percentage of whole duration

27. peak velocity during closure

28. minimal velocity during closure

29. position: $x$-value of closure onset

30. voicing into closure

31. VOT 
The aim of this study is to find out to which degree these parameters are used to mark the contrast between the stops. In order to do this, one has to make the parameters comparable. For example, to find out whether voicing into closure or movement amplitude during V1 is more important to characterise $/ \mathrm{k}^{\prime} /$ and to set it apart from $/ \mathrm{k}^{\mathrm{h}} /$, one has to develop a scale which is independent from value and measuring unit.

In order to do this, the minimal and maximal values of each parameter, independent of the consonant were set to 0 and 100, respectively, and the values in between were converted into values on this scale. This was done separately for each speaker. To reduce the influence of outliers, the means of the three highest and the three lowest values were taken as maximal and minimal values for each parameter. For example, the three highest values of velocity for $\mathrm{SH}$ are $19.7492,19.3158$ and $19.0682 \mathrm{~cm} / \mathrm{s}$, the minimal values are $0.2739,0.4157$, $1.7605 \mathrm{~cm} / \mathrm{s}$. The mean value for the maxima, 19.3777 , was set to 100 , the mean for the minima, 0.8167 was set to 0 . For all the values in between the two a place on the scale was calculated. For $/ \mathrm{k}^{\prime} /$ in $/ \mathrm{ak}$ ' a/ in the third repetition, which was $15.7507 \mathrm{~cm} / \mathrm{s}$, this meant that it now was 80.4589 on the scale. This procedure can be seen in the following table:

Table 3: Conversion of measured values into scale values

\begin{tabular}{|lccc|} 
measured values: & $0.8167 \mathrm{~cm} / \mathrm{s}$ & $15.7507 \mathrm{~cm} / \mathrm{s}$ & $19.3777 \mathrm{~cm} / \mathrm{s}$ \\
\cline { 2 - 4 } scale values: & 0 & 80.4589 & 100 \\
\hline
\end{tabular}

After all the measured values had been converted into values on this neutral scale they were grouped according to consonants and parameters. For each parameter and consonant the arithmetic mean was calculated. Now the importance of a single parameter for the characterisation of a consonant could be estimated. Parameters that have a very high or very low scale value, which is, following from that, close to maximum or minimum are characteristic for the consonant, whereas parameters that have an average value are less important.

To find out how important a parameter is for marking the contrast between two consonants, the difference between the arithmetic means of scale values of two consonants was calculated. To give an example, if one looks at closure duration of speaker HS, the mean value on the scale for $/ \mathrm{g} /$ is 20.7692 , the one for $/ \mathrm{k}^{\prime} /$ is 70.9138 . The contrast between the two is the difference, 50.1446 .

After an analysis of variance the parameters that did not produce a significant difference were excluded, since they are not useful to distinguish among the stops. For the remaining parameters a hierarchy was set up according to the scale value contrast the parameters produced.

\section{$3 \quad$ Results and Discussion}

It turned out that some of the parameters are not useful to distinguish among the stops. Those are listed in section 3.1. Furthermore, this section presents some general features of the stops. Section 3.2. will present the hierarchy of parameters that are useful to contrast the stops. Section 3.3. describes temporal and spatial characteristics for the three stops. Section 3.4. deals with differences between the two speakers. 


\subsection{Similarities of the three stops}

There are certain features that are shared by the three stops. The first point is that there is movement during closure. The direction of the movement depends on the vowel context. The tongue moves forward in the vowel contexts $/ \mathrm{a} \_\mathrm{a} /, / \mathrm{a} \_\mathrm{i} /, / \mathrm{u} \_\mathrm{a} /, / \mathrm{u} \_\mathrm{i} /$ and $/ \mathrm{u} \_\mathrm{u} / \mathrm{I}$. It moves backwards if the vowel context is /a_u/, /i_a/,/i_i/,/i_u/. This means that it moves backwards only if it has to come from a fronted position to a back position or if $\mathrm{V} 1$ is /i/. There is very much movement when $\mathrm{V} 1$ is /a/ and hardly any if $\mathrm{V} 1$ is $/ \mathrm{i} /$. For $\mathrm{V} 1=/ \mathrm{u} /$ the loops are a little bigger than for $\mathrm{V} 1=/ \mathrm{i} /$.

Nearly all productions of the stops have their velocity peak during V1. Furthermore, it turned out that the peak velocity during closure and V1 is about equal, the same is true for the minimal velocity during V2.

Similarly, determining loop ways (parameter: Euclidean distance/movement amplitude) did not produce a significant result, neither for closure nor for the vowels. Furthermore, the Euclidean distance and the movement amplitude for the VCV-sequence were about equal for all the stops. From the V1-parameters Euclidean distance did not produce a significant result. In general V1 turned out to be less influencing than V2.

Furthermore, if one looks at position independently of vowel context and speaker, there is no significant difference in the x-coordinates between the consonants. Even if $\mathrm{SH}$ produces $/ \mathrm{g} /$ significantly further back than $/ \mathrm{k}^{\mathrm{h}} /(\mathrm{p}=0.008)$, there is no such difference for HS (cf. figure 3 for $\mathrm{SH}$ ).

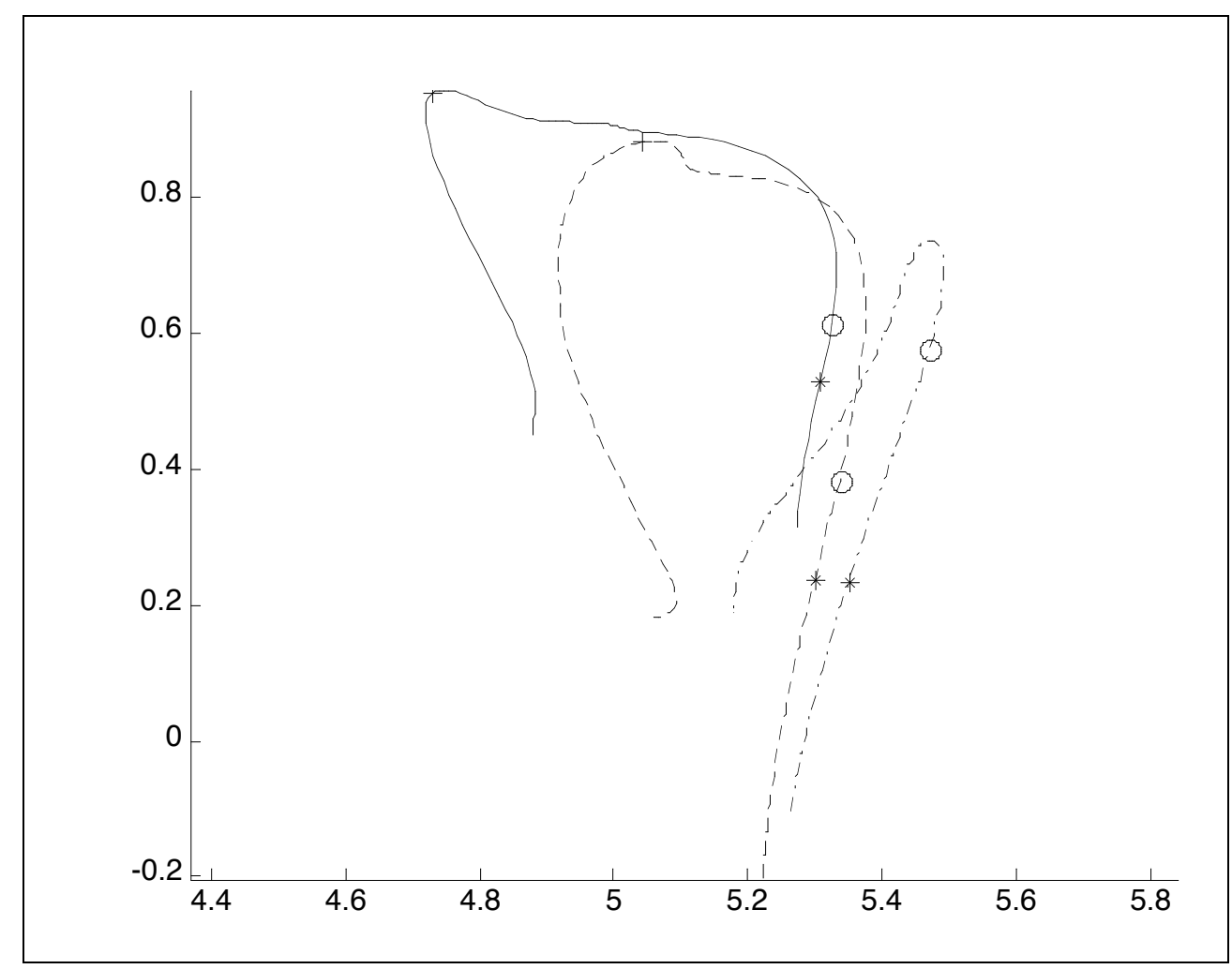

Figure 3: Typical productions of $/ g /\left(\right.$ dash-dot), $/ k^{\prime} /$ (solid line) and $/ k^{h} /$ (dashed) in $/ a$ al context. $/ \mathrm{g} /$ is produced significantly further back than the other stops. Closure onset (o), burst (+) and velocity peaks (*) are marked. There is no burst for /g/. 
However, including vowel context in the analysis, the result is that, if $\mathrm{V} 1 \mathrm{is} / \mathrm{i} /$, closure onset is more forward than if it is $/ \mathrm{u} /$ or $/ \mathrm{a} /$. This difference is very significant for both speakers. Furthermore, speaker HS produces closure onset more forward in contexts with $\mathrm{V} 1=/ \mathrm{a}$ / than with $\mathrm{V} 1=/ \mathrm{u} /$. For speaker $\mathrm{SH}$ it is just the other way round. Those differences are also significant.

\subsection{Parameter hierarchy}

Some parameters produce a significant difference between the consonants, independently of the speaker. Others are speaker dependent. The later ones were not regarded as distinguishing the three consonants. The parameters that distinguish between the stops independently of the speaker where put on a hierarchy according to the scale discussed above. The following hierarchy of parameters can be established split by speakers:

Table 4: Parameters that distinguish the stops significantly, ordered by contrast on the scale from high to low. The asterisks show the level of significance (*: $p<0.05$, **: $p<0.01, * * *: p<0.001)$

\section{speaker: SH}

\section{3 way contrast}

- closure duration $\left(\mathrm{g}<\mathrm{k}^{\mathrm{h}}<\mathrm{k}^{\prime}\right)^{* * *}$

- percentage of complete duration for $\mathrm{V} 2\left(\mathrm{k}^{\mathrm{h}}<\mathrm{k}<\mathrm{g}\right) * * *$

- duration of $\mathrm{V} 2\left(\mathrm{k}^{\mathrm{h}}<\mathrm{k}^{\prime}<\mathrm{g}\right) * * *$

\section{2 way contrast /g/ vs. /k'/}

- voicing into closure $\left(\mathrm{k}^{\prime}<\mathrm{g}\right)^{* * *}$

- closure duration $\left(\mathrm{g}<\mathrm{k}^{\prime}\right)^{* * *}$

- percentage of complete duration for closure $(\mathrm{g}<\mathrm{k})^{\prime} * * *$

- percentage of complete movement for $\mathrm{V} 1\left(\mathrm{k}^{\prime}<\mathrm{g}\right) * * *$

- duration of V1 $\left(\mathrm{k}^{\prime}<\mathrm{g}\right)^{* * *}$

- percentage of complete duration for $\mathrm{V} 2\left(\mathrm{k}^{\prime}<\mathrm{g}\right)^{* * *}$

- minimal velocity during closure $(\mathrm{k}<\mathrm{g})^{*}$

- duration of V2 $\left(\mathrm{k}^{\prime}<\mathrm{g}\right)^{* * *}$

- duration $\left(\mathrm{g}<\mathrm{k}^{\prime}\right)^{* *}$ speaker: HS

\section{3 way contrast}

- closure duration $\left(\mathrm{g}<\mathrm{k}^{\mathrm{h}}<\mathrm{k}\right.$ ') $* * *$

- percentage of complete duration for $\mathrm{V} 2\left(\mathrm{k}^{\mathrm{h}}<\mathrm{k},<\mathrm{g}\right)$ $* * *$ for $/ \mathrm{g} / \mathrm{vs}$. $/ \mathrm{k}^{\prime} /$ and $/ \mathrm{g} / \mathrm{vs}$. $/ \mathrm{k}^{\mathrm{h}} /$ $* *$ for $/ \mathrm{k}^{\prime} / \mathrm{vs}$. $/ \mathrm{k}^{\mathrm{h}} /$

- duration of V2 $\left(\mathrm{k}^{\mathrm{h}}<\mathrm{k}^{\prime}<\mathrm{g}\right)$ *for /g/ vs. /k'/ $* * *$ for $/ \mathrm{g} / \mathrm{vs}$. $/ \mathrm{k}^{\mathrm{h}} /$ and $/ \mathrm{k} / \mathrm{vs} . / \mathrm{k}^{\mathrm{h}} /$

2 way contrast /g/ vs. /k'/

- closure duration $\left(\mathrm{g}<\mathrm{k}^{\prime}\right) * * *$

- percentage of complete duration for closure $(\mathrm{g}<\mathrm{k}$ ') $* * *$

- percentage of complete movement for $\mathrm{V} 1\left(\mathrm{k}^{\prime}<\mathrm{g}\right)$

- percentage of complete movement for $\mathrm{V} 2\left(\mathrm{k}^{\prime}<\mathrm{g}\right)^{*}$

- duration of V1 $\left(\mathrm{k}^{\prime}<\mathrm{g}\right) * * *$

- duration $\left(\mathrm{g}<\mathrm{k}^{\mathrm{h}}<\mathrm{k}^{\prime}\right)^{* * *}$

- voicing into closure $\left(\mathrm{k}^{\prime}<\mathrm{g}\right) * * *$

- minimal velocity during closure $(\mathrm{k}<\mathrm{g})^{*}$

- duration of V2 $\left(\mathrm{k}^{\prime}<\mathrm{g}\right)^{*}$ 


\section{2 way contrast $/ \mathrm{g} / \mathrm{vs}$. $/ \mathrm{k}^{\mathrm{h}} /$}

- voicing into closure $\left(\mathrm{k}^{\mathrm{h}}<\mathrm{g}\right) * * *$

- VOT $\left(\mathrm{g}<\mathrm{k}^{\mathrm{h}}\right) * * *$

- percentage of complete duration for $\mathrm{V} 2\left(\mathrm{k}^{\mathrm{h}}<\mathrm{g}\right) * * *$

- percentage of complete movement for $\mathrm{V} 1\left(\mathrm{k}^{\mathrm{h}}<\mathrm{g}\right) * * *$

- duration of V1 $\left(\mathrm{k}^{\mathrm{h}}<\mathrm{g}\right) * * *$

- duration of V2 $\left(\mathrm{k}^{\mathrm{h}}<\mathrm{g}\right) * * *$

- movement amplitude of V2 $\left(\mathrm{k}^{\mathrm{h}}<\mathrm{g}\right) * * *$

- closure duration $\left(\mathrm{g}<\mathrm{k}^{\mathrm{h}}\right) * * *$

- minimal velocity during closure $\left(\mathrm{k}^{\mathrm{h}}<\mathrm{g}\right) * *$

- percentage of whole duration for closure $\left(\mathrm{g}<\mathrm{k}^{\mathrm{h}}\right)$ ***

- minimal velocity during $\mathrm{V} 1\left(\mathrm{~g}<\mathrm{k}^{\mathrm{h}}\right) * *$

- peak velocity during V2 $\left(\mathrm{g}<\mathrm{k}^{\mathrm{h}}\right)^{*}$

- movement amplitude for V1 $\left(\mathrm{k}^{\mathrm{h}}<\mathrm{g}\right) * *$

- duration $\left(\mathrm{g}<\mathrm{k}^{\mathrm{h}}\right) *$

2 way contrast $/ k^{\prime} /$ vs. $/ \mathbf{k}^{\mathrm{h}} /$

- $\operatorname{VOT}\left(\mathrm{k}^{\prime}<\mathrm{k}^{\mathrm{h}}\right) * * *$

- closure duration $\left(\mathrm{k}^{\mathrm{h}}<\mathrm{k}^{\prime}\right) * * *$

- percentage of complete movement for closure $\left(\mathrm{k}^{\mathrm{h}}<\mathrm{k}\right.$ ') $* * *$

- percentage of complete movement for $\mathrm{V} 2\left(\mathrm{k}^{\mathrm{h}}<\mathrm{k}^{\prime}\right) * * *$

- duration of V2 $\left(\mathrm{k}^{\mathrm{h}}<\mathrm{k},\right) * * *$

- movement amplitude of V2 $\left(\mathrm{k}^{\mathrm{h}}<\mathrm{k}^{\prime}\right) * *$

\section{2 way contrast $/ g /$ vs. $/ \mathbf{k}^{\mathrm{h}} /$}

- closure duration $\left(\mathrm{g}<\mathrm{k}^{\mathrm{h}}\right) * * *$

- percentage of complete movement for closure $\left(\mathrm{g}<\mathrm{k}^{\mathrm{h}}\right) * * *$

- $\operatorname{VOT}\left(\mathrm{g}<\mathrm{k}^{\mathrm{h}}\right) * * *$

- percentage of complete duration for $\mathrm{V} 2\left(\mathrm{k}^{\mathrm{h}}<\mathrm{g}\right) * * *$

- percentage of complete duration for $\mathrm{V} 1\left(\mathrm{k}^{\mathrm{h}}<\mathrm{g}\right) * * *$

- duration of V1 $\left(\mathrm{k}^{\mathrm{h}}<\mathrm{g}\right) * * *$

- duration of $\mathrm{V} 2\left(\mathrm{k}^{\mathrm{h}}<\mathrm{g}\right) * * *$

- movement amplitude for V2 $\left(\mathrm{k}^{\mathrm{h}}<\mathrm{g}\right) * * *$

- movement amplitude for V1 $\left(\mathrm{k}^{\mathrm{h}}<\mathrm{g}\right) * * *$

- voicing into closure $\left(\mathrm{k}^{\mathrm{h}}<\mathrm{g}\right) * * *$

- minimal velocity during closure $\left(\mathrm{k}^{\mathrm{h}}<\mathrm{g}\right) *$

- minimal velocity during V1 $\left(\mathrm{g}<\mathrm{k}^{\mathrm{h}}\right) *$

- peak velocity during V2 $\left(\mathrm{g}<\mathrm{k}^{\mathrm{h}}\right)^{*}$

- duration $\left(\mathrm{g}<\mathrm{k}^{\mathrm{h}}\right) * *$

2 way contrast $/ k^{\prime} /$ vs. $/ k^{h} /$

- $\operatorname{VOT}\left(\mathrm{k}^{\prime}<\mathrm{k}^{\mathrm{h}}\right) * * *$

- duration of V2 $\left(\mathrm{k}^{\mathrm{h}}<\mathrm{k}\right.$ ') ***

- movement amplitude for $\mathrm{V} 2\left(\mathrm{k}^{\mathrm{h}}<\mathrm{k}^{\prime}\right)^{*}$

- percentage of complete movement for $\mathrm{V} 2\left(\mathrm{k}^{\mathrm{h}}<\mathrm{k}\right.$ ')**

- closure duration $\left(\mathrm{k}^{\mathrm{h}}<\mathrm{k}^{\prime}\right) * * *$

- percentage of complete movement for closure $\left(\mathrm{k}^{\mathrm{h}}<\mathrm{k}^{\prime}\right) * *$

Closure duration is the most important parameter, for speaker HS it exceeds voicing into closure in relevance by far. The second and third parameters which enable a three way distinction are percentage of complete duration for V2 and duration of V2. The distinction between $/ \mathrm{g} /$ and $/ \mathrm{k}^{\prime} /$ is furthermore built on voicing and V1-parameters, but for speaker HS the V1-parameters are more important than voicing. $/ \mathrm{g} /$ and $/ \mathrm{k}^{\mathrm{h}} /$ are contrasted by voicing, aspiration and vowel-parameters. Again, speaker HS does not base the distinction primarily on voicing but on other parameters. For $/ \mathrm{k}^{\prime} /$ and $/ \mathrm{k}^{\mathrm{h}} / \mathrm{V} 2$-parameters are the most important parameters after closure and VOT. The importance of duration of segments for the contrast is illustrated in the diagrams below (figures 5 and 6).

Three conclusions can be drawn from that: Firstly, the "voicing contrast" in Korean is a contrast based not only on voicing but on a conglomerate of parameters of which voicing can be one. Secondly, at least for Korean to base a three way "voicing"-contrast on voicing only seems to be a highly unlikely strategy. Thirdly, even in the distinctions between only two stops, for example $/ \mathrm{g} /$ and $/ \mathrm{k}$ /, voicing does not necessarily have to be the most important parameter. Looking at it this way, Korean does not contradict to the general tendency in the languages of the world because the contrast is not built primarily on voicing. 


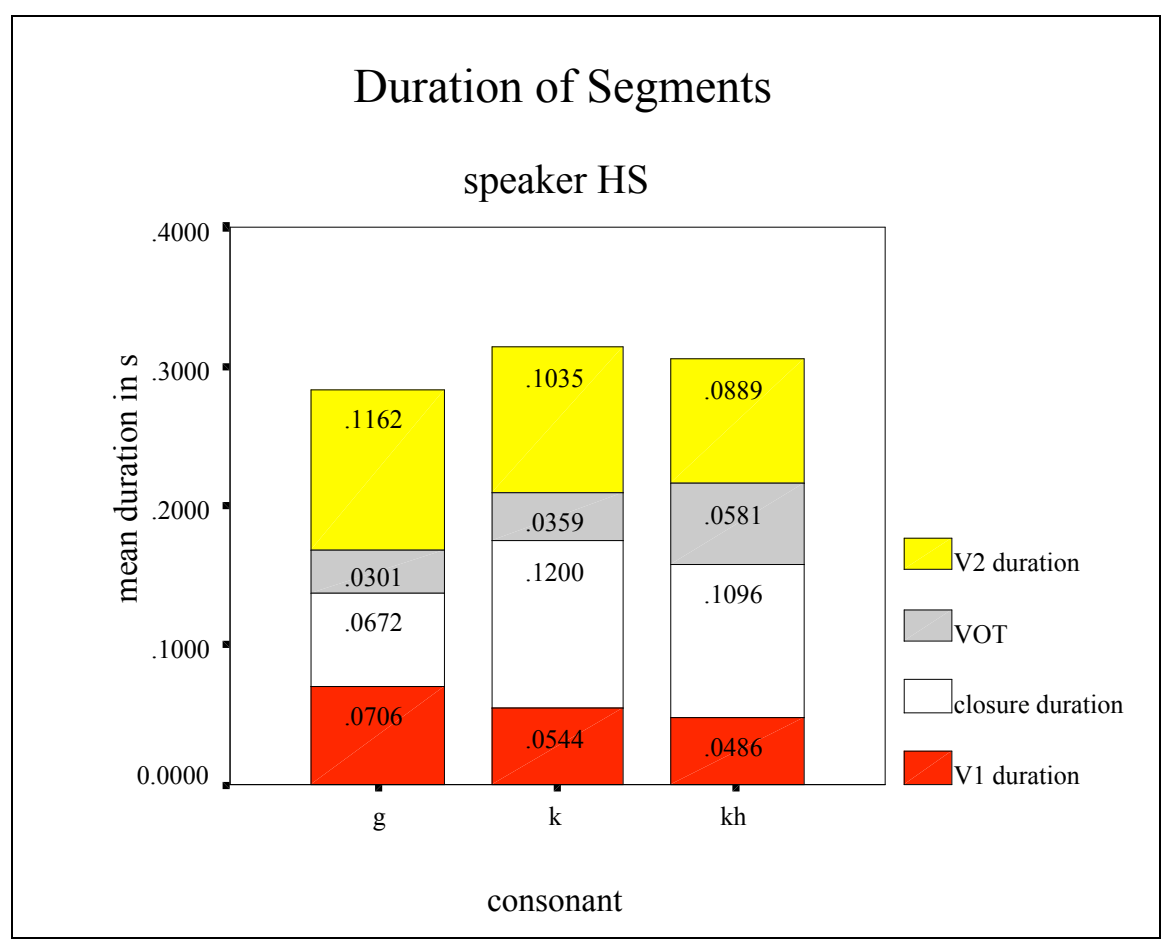

Figure 5: Duration of segments for speaker HS

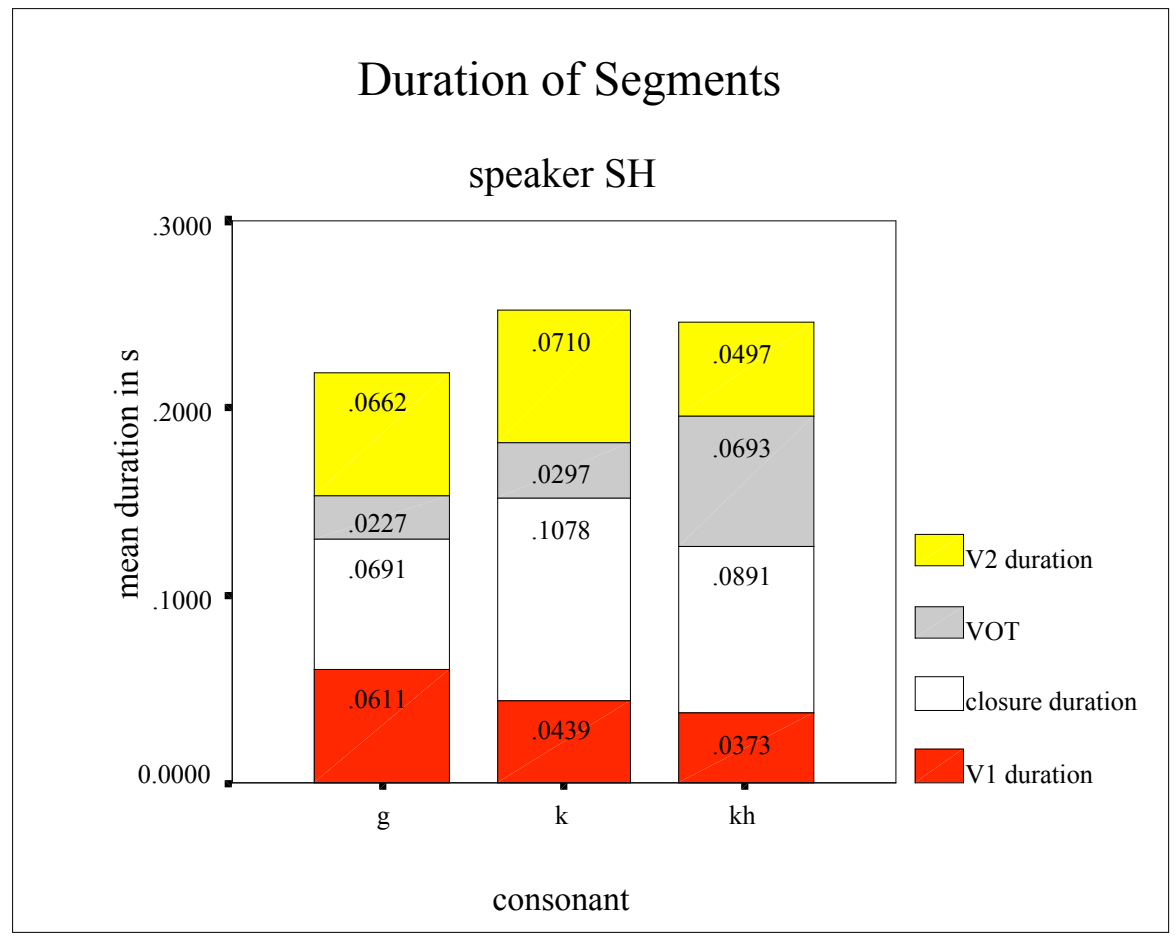

Figure 6: Duration of segments for speaker SH

\subsection{Characteristics of the consonants}

Each consonant will now be described on the basis of the parameters from the catalogue. 
Korean $/ \mathrm{g} /$ is often not a real stop, because it is frequently produced without closure. If there is a closure, it is very short, shorter than for the other two consonants. Consequently, the percentage of closure is also very low. Because there is often no real closure, the tongue is not stopped abruptly, so that the minimum velocity during closure is higher than for the other stops. /g/ in general has only very low velocity differences, it has the highest minimum velocity of the three consonants, but the peak velocities are not very high. The second important characteristic of $/ \mathrm{g} /$ is its long voicing into closure. Often the consonant is fully voiced. Its VOT is shorter than the ones for the other two consonants. The vowels before and after $/ \mathrm{g} /$ are longer than the ones surrounding the other consonants. Following from that, the percentages for both vowels are very high.

The most important characteristic of $/ \mathrm{k}^{\prime} /$ is its long closure, consequently, the percentage of closure is also high. During the long closure, a velocity minimum is reached which is lower than for $/ \mathrm{g} /$, so that the two sounds can be distinguished by that. The vowels for $/ \mathrm{k}^{\prime} /$ are shorter than in $/ \mathrm{g} /$, even if they are longer than for $/ \mathrm{k}^{\mathrm{h}} /$. The percentages of the vowels are consequently also shorter than in the $/ \mathrm{g} /$-context. The VOT of $/ \mathrm{k}^{\prime} /$ is considerably shorter than the one for $/ \mathrm{k}^{\mathrm{h}} /$, but longer than for $/ \mathrm{g} /$. With voicing into closure it is just the other way round.

$/ \mathrm{k}^{\mathrm{h}} /$ is an aspirated stop, and this is also its most important characteristic. Its VOT is the highest of all the consonants. Its second important characteristic is the short duration for both vowels, the duration of V1 sets it apart from $/ \mathrm{g} /$, the one of $\mathrm{V} 2$ from $/ \mathrm{k} \%$. Its closure duration is shorter than the one of $/ \mathrm{k}^{\prime} /$ but longer than for $/ \mathrm{g} /$.

\subsection{Individual use of the parameters by the speakers}

The main difference between the speakers is that speaker SH uses voicing into closure and VOT to a much higher degree than the other speaker. Furthermore, for $/ g /$ he often does not produce a real closure. There are a number of other parameters where $\mathrm{SH}$ produces a significant difference but HS shows none, however, the levels of significance are normally low:

- duration of V1 for $/ \mathrm{k}^{\prime} / \mathrm{vs} . / \mathrm{k}^{\mathrm{h}} / *$,

- minimal velocity during V1 for $/ \mathrm{g} / \mathrm{vs} . / \mathrm{k}^{\prime} / * *$,

- movement amplitude of $\mathrm{V} 2$ for $/ \mathrm{g} / \mathrm{vs} . / \mathrm{k} / *$,

- Euclidean distance of V2 for $/ \mathrm{g} / \mathrm{vs}$. $/ \mathrm{k}^{\prime} / \mathrm{k}^{*}$ as well as for $/ \mathrm{k}^{\prime} / \mathrm{vs} . / \mathrm{k}^{\mathrm{h}} / * * *$,

- Euclidean distance/movement amplitude for $/ \mathrm{g} / \mathrm{vs} . / \mathrm{k}^{\prime} / * *$,

- minimal velocity for $/ \mathrm{g} / \mathrm{vs}$. $/ \mathrm{k}^{\prime} / *$.

Those parameters are centred around the distinction /g/ vs. /k'/ and may be a result of the different production of $/ \mathrm{g} /$ for $\mathrm{SH}$ as opposed to HS.

On the other hand, there are also parameters where HS shows a significant difference and SH shows none:

- $\quad$ minimal velocity during V1 for $/ \mathrm{k}^{\prime} / \mathrm{vs} . / \mathrm{k}^{\mathrm{h}} / *$,

- percentage of complete duration for closure for $/ \mathrm{g} / \mathrm{vs} . / \mathrm{k}^{\mathrm{h}} / * * *$,

- movement amplitude of closure for $/ \mathrm{g} / \mathrm{vs} . / \mathrm{k}^{\prime} / * * *$ as well as $/ \mathrm{g} / \mathrm{vs}$. $/ \mathrm{k}^{\mathrm{h}} / * *$,

- Euclidean distance of closure for $/ \mathrm{g} / \mathrm{vs} . / \mathrm{k}^{\mathrm{h}} / *$,

- Euclidean distance/movement amplitude for $/ \mathrm{g} / \mathrm{vs} . / \mathrm{k}^{\mathrm{h}} / *$.

HS strengthens the parameter closure duration by other closure related parameters (2-4 in the list), which SH does not. It is possible that HS, who uses voicing into closure and aspiration to 
a lower degree, makes up for this by using other parameters to a higher degree than SH to discriminate among the stops clearly enough.

\section{Conclusion}

The major result of this study is that closure duration is the most important parameter for the distinction of Korean $/ \mathrm{g} /, / \mathrm{k}^{\prime} /$ and $/ \mathrm{k}^{\mathrm{h}} /$. It is more important than voicing or aspiration because it creates a three way contrast and not only a two way contrast. There are two other parameters that exhibit a two way contrast, namely percentage of complete duration for V2 and duration of V2. Thus the "voicing"-contrast is primarily one not based on a laryngeal characteristic, namely voicing, but on the articulatory characteristics of duration of vowel and closure.

Other important parameters for contrasting $/ \mathrm{g} /$ and $/ \mathrm{k}$ '/ include voicing into closure and duration of V1. For contrasting $/ \mathrm{g} /$ and $/ \mathrm{k}^{\mathrm{h}} /$ the VOT and a number of characteristics of $\mathrm{V} 1$ are important. $/ \mathrm{k}^{\prime} /$ and $/ \mathrm{k}^{\mathrm{h}} /$ differ primarily in VOT.

Speakers seem to apply different strategies in distinguishing their stops from each other. In this study, speaker SH used VOT and voicing more intensively than speaker HS, who used other parameters.

Even if significant differences between the parameters could be found, this does not imply automatically that those parameters are used by the hearer to discriminate among the sounds. The parameters simply describe the production of the stops.

So far, this study has treated the parameters as being independent of vowel context which, however, they are not. For this reason, the results are only partly reliable and have to be looked at in greater detail.

\section{References}

Cho, T., Jun S. \& Ladefoged, P. 2002. Acoustic and aerodynamic correlates of Korean stops and Fricatives. In Journal of Phonetics 30,2: 193-228.

Choi, H. 2002. Acoustic Cues for the Korean top Contrast - Dialectal Variation. ZAS Papers in Linguistics 28 : $1-12$.

Fry, D.B. 1982. The Physics of Speech. Cambridge: Cambridge University Press.

Han, M.S. \& Weitzman, R.S. 1970. Acoustic Features of Korean /P,T, K/, /p,t,k/ and /p $\mathrm{p}^{\mathrm{h}}, \mathrm{t}^{\mathrm{h}}, \mathrm{k}^{\mathrm{h}} /$. Phonetica 22 : 112-128.

Houde, R. A. 1968. A Study of Tongue Body Motion During Selected Speech Sounds. Unpublished Ph.D. dissertation. Speech Communications Research Laboratory, Inc. Santa Barbara, California.

Kagaya, R. 1971. Laryngeal Gestures in Korean Stop Consonants. Annual Report of the Research Institute for Logopedics and Phoniatrics 2: 15-23.

Kagaya, R. 1974. A fiberscopic and acoustic study of the Korean stops, affricates and fricatives. Journal of Phonetics 2: 161-180.

Kent, R. \& Moll, K. 1975. Cinefluographic analyses of selected lingual consonants. Journal of Speech and Hearing Research 15: 453-473.

Kim, H. 1996. Kontrastive Wortphonologie des Deutschen und Koreanischen. Unpublished Ph.D. dissertation. Ludwig-Maximilians-Universität, München.

Klatt, D. 1975. Voice onset time, frication, and aspiration in word-initial consonant clusters. Journal of Speech and Hearing Research 18: 686-706.

Löfqvist, A., Gracco, V.L. \& Nye, P.W. 1993. Recording speech movement using magetometers: One laboratory's experience. Forschungsberichte des Insituts für Phonetik und Sprachliche Kommunikation München 31: 143-162. 
Löfqvist, A., Gracco, V.L. 2002. Control of oral closure in lingual stop consonant production. Journal of the Acoustical Society of America 111,6: 2811-2827.

Lee, H. B. 1999. Korean. In: IPA (ed.) Handbook of the IPA. Cambridge: Cambridge University Press; 120-123.

Luce, P.A. \& Charles-Luce, J. 1985. Contextual effects on vowel duration, closure duration, and the consonant/vowel ratio in speech production. Journal of the Acoustical Society of America 78,6: 1949-57.

Maddieson, I. 1984. Patterns of Sounds. Cambridge: Cambridge University Press.

Maddieson, I. 2003. Phonological typology in geographical perspective. Proceedings of the $15^{\text {th }} I C P h S$ Barcelona: 719-722.

Mooshammer, C., Hoole, P. \& Kühnert, B. 1995. On loops. Journal of Phonetics 23: 3-21.

Ohala, J.J. 1983. The Origin of Sound Patterns in Vocal Tract Contstraints. In: P.F. MacNeilage (ed.) The Production of Speech. New York: Springer; 189-216.

Perrier, P., Payan, Y., Zandipour, M. \& Perkell, J. 2003. Influences of tongue biomechanics on speech movements during the production of velar stop consonants : A modeling study. Journal of the Acoustical Society of America 114: 1582-1599.

Sawashima, M. \& Park, H.S. 1979. Laryngeal Adjustments for Syllable Final Stops in Korean: Some Preliminary Results of Fiberoptic Observation. Annual Report of the Research Institute for Logopedics and Phoniatrics 13, 83-89.

Silverman, D. \& Jongho, J. 1994. Aerodynamic Evidence for Articulatory Overlap in Korean. Phonetica 51: 210-220.

Umeda, H. \& Umeda N. 1965. Acoustical Features of Korean 'Forced' Consonants. Gengo Kenkyu 48: 23-33. 